\title{
Luminescent Lanthanide Complexes for Advanced Photonics Applications
}

\author{
Yu Kyung Eom, Jung Ho Ryu, Hwan Kyu Kim*
}

Department of Advanced Materials Chemistry and WCU Center for Next Generation Photovoltaic Systems, Korea University, Jochiwon, Chungnam 339-700, Republic of Korea.

\begin{abstract}
Luminescent lanthanide complexes have been overviewed for advanced photonics applications. Lanthanide(III) ions $\left(\mathrm{Ln}^{3+}\right)$ were encapsulated by the luminescent ligands such as metalloporphyrins, naphthalenes, anthracene, push-pull diketone derivatives and boron dipyrromethene(bodipy). The energy levels of the luminescent ligands were tailored to maintain the effective energy transfer process from luminescent ligands to $\mathrm{Ln}^{3+}$ ions for getting a higher optical amplification gain. Also, key parameters for emission enhancement and efficient energy transfer pathways for the sensitization of $\mathrm{Ln}^{3+}$ ions by luminescent ligands were investigated. Furthermore, to enhance the optophysical properties of novel luminescent $\mathrm{Ln}^{3+}$ complexes, aryl ether-functionalized dendrons as photon antennas have been incorporated into luminescent $\mathrm{Ln}^{3+}$ complexes, yielding novel $\mathrm{Ln}^{3+}$-cored dendrimer complex such as metalloporphyrins, naphthalenes, and anthracenes bearing the Fréchet aryl-ether dendrons, namely, $\left(\mathrm{Er}^{3+}-[\mathrm{G} n-\mathrm{Pt}-\mathrm{Por}]_{3}\right.$ (terpy), $\mathrm{Er}^{3+}-[\mathrm{G} n-$ $\mathrm{Naph}]_{3}$ (terpy) and $\mathrm{Er}^{3+}-[\mathrm{Gn}-\mathrm{An}]_{3}($ terpy)). These complexs showed much stronger near-IR emission bands at 1530 $\mathrm{nm}$, originated from the $4 f-4 f$ electronic transition of the first excited state $\left({ }^{4} \mid 13 / 2\right)$ to the ground state $\left(\left.{ }^{4}\right|_{15 / 2}\right)$ of the partially filled $4 f$ shell. A significant decrease in the fluorescence of metalloporphyrins, naphthalenes and anthracene ligand were accompanied by a strong increase in the near IR emission of the $\mathrm{Ln}^{3+}$ ions. The near IR emission intensities of $\mathrm{Ln}^{3+}$ ions in the lanthanide(III)-encapsulated dendrimer complexes were dramatically enhanced with increasing the generation number $(n)$ of dendrons, due to the site-isolation and the light-harvesting (LH) effects. Furthermore, it was first attempted to distinguish between the site-isolation and the light-harvesting effects in the present complexes. In this review, synthesis and photophysical studies of inert and stable luminescent $\mathrm{Ln}^{3+}$ complexes will be dealt for the advanced photonics applications. Also, the review will include the exploratory investigation of the key parameters for emission enhancement and the effective energy transfer pathways from luminescent ligands to $\mathrm{Ln}^{3+}$ ions with $\mathrm{Ln}^{3+}-$ chelated prototype complexes.
\end{abstract}

*To whom correspondence should be addressed. E-mail: hkk777@korea.ac.kr ReceivedJanuary 9, 2012; accepted February 20, 2012

\section{Introduction}

Advanced photonic devices based on semiconductors and inorganic materials have continuously been pursued for the realization of superhigh speed communication systems of large capacity optical communication, information storage, and processing. However, the currently existing limitations of these materials on the performance, extensive research on the development of new advanced materials is essential to overcome such limitations and to achieve photonic devices for the next generation superhigh speed communications. With regard to this, the organic polymeric materials have been considered as such future photonic materials and their main advantages, compared with semiconductors and inorganic materials, are as follows: ease of property control and synthetic feasibility through molecular chemistry, fast response time and large broad bandwidth, low cost, good processibility, and simple device manufacturing process at low temperatures, and ease of integrated device fabrication. However, their thermal instability in the optical property and high optical transmission loss in the practical use at wavelength of 1.30 or $1.53 \mu \mathrm{m}$ are still limited in real device applications. High transmission loss has been attributed to the optical absorption by the inherent presence of $\mathrm{C}-\mathrm{H}$ overtone band in organic polymers. To compensate for the above mentioned shortcomings, the development of integrated planar waveguide optical amplifiers utilizing the basic principle of optical amplification in optical fibers for telecommunication is extremely high in demand. In particular, integrated optical amplifier wavelength division multiplexing(WDM) devices are recognized to be essential for successfully realizing photonic devices in WDM technology, which has attracted much attention because of its paramount importance in superhigh speed communication systems. Despite such needs, the problem still remains in the materials for the use in the real optical amplifiers. ${ }^{1}$

At present, erbium $\left(\mathrm{Er}^{3+}\right)$-doped silica amplifiers are widely used for the optical telecommunication can maintain very low loss (below $0.18 \mathrm{~dB} / \mathrm{km}$ ) when operated at wavelength of $1.53 \mu \mathrm{m}$. But, the poor solubility of lanthanide cations $\left(\mathrm{Ln}^{3+}\right)$ in conventional inorganic/organic media leads to low amplification property. In addition, $\mathrm{Er}^{3+}$-doped silica amplifiers is limited to $100-1000$ ppm. If higher than the limiting concentration is to be employed, $\mathrm{Er}^{3+}$ ion interaction between themselves would cause non-radiative process to occur, hence rapidly reducing the amplification gain. For these reasons, it is not possible to obtain the amplification gain of higher than $30 \mathrm{~dB}$ with $\mathrm{Er}^{3+}$-doped silica optical fibers for developing integrated planar waveguide amplifiers. ${ }^{2}$

In order to enhance the luminescence intensity, luminescent 
ligands are being used to excite the $\operatorname{Ln}^{3+}$ ions via an energy transfer from the luminescent ligands to the $\mathrm{Ln}^{3+}$ ions. The development of luminescent $\mathrm{Ln}^{3+}$ complexes based on the energy transfer phenomena by using the supramolecular complexes as organic ligands has been extensively studied and attracted considerable attention because of their academic interests and potential utility in a wide variety of applications, such as planar waveguide amplifiers, plastic lasers, and light-emitting diodes. ${ }^{3-15}$ In most cases, luminescent $\mathrm{Ln}^{3+}$ complexes consist of $\mathrm{Ln}^{3+}$ ion and chelating luminescent ligand which acts as a sensitizer that transfers excitation energy to the encapsulated $\mathrm{Ln}^{3+}$ ion; the presence of this kind of ligand overcomes the lanthanide ion's intrinsically low luminescence intensity by direct excitation of the $\mathrm{Ln}^{3+}$ ion having low absorption and emission crosssections. Luminescent ligands efficiently absorb photons and transfer the excited energy to the central $\mathrm{Ln}^{3+}$ ions. The central $\mathrm{Ln}^{3+}$ ions accumulate energy from the antenna chromophores, producing a strong and narrow bandwidth emission. This sensitization process is much more effective than the direct excitation of $\mathrm{Ln}^{3+}$ ions, since the absorption coefficients of organic chromophores are many orders of magnitude larger than the intrinsically low molar absorption coefficients (typically $1-10 \mathrm{M}^{-1} \mathrm{~cm}^{-1}$ ) of $\mathrm{Ln}^{3+}$ ions.

Lanthanide-containing near-infrared(NIR)-emitting compounds ${ }^{16}$ are classified according to the synthetic strategy used to encapsulate the metal ion starting with macrocyclic compounds, ${ }^{17}$ then moving to acyclic receptors before describing sensitization with transition metal ions and, finally, various other approaches leading to new materials. Numerous NIR-emitting lanthanide-porphyrin complexes have been reported, particularly with $\mathrm{Yb}^{3+}$ ion in view of the favorable energy of the porphyrin triplet state. ${ }^{17}$ Porphyrins display rich photochemical properties and various application for sensitizing $\mathrm{Ln}^{3+}$ luminescence. ${ }^{18,19}$
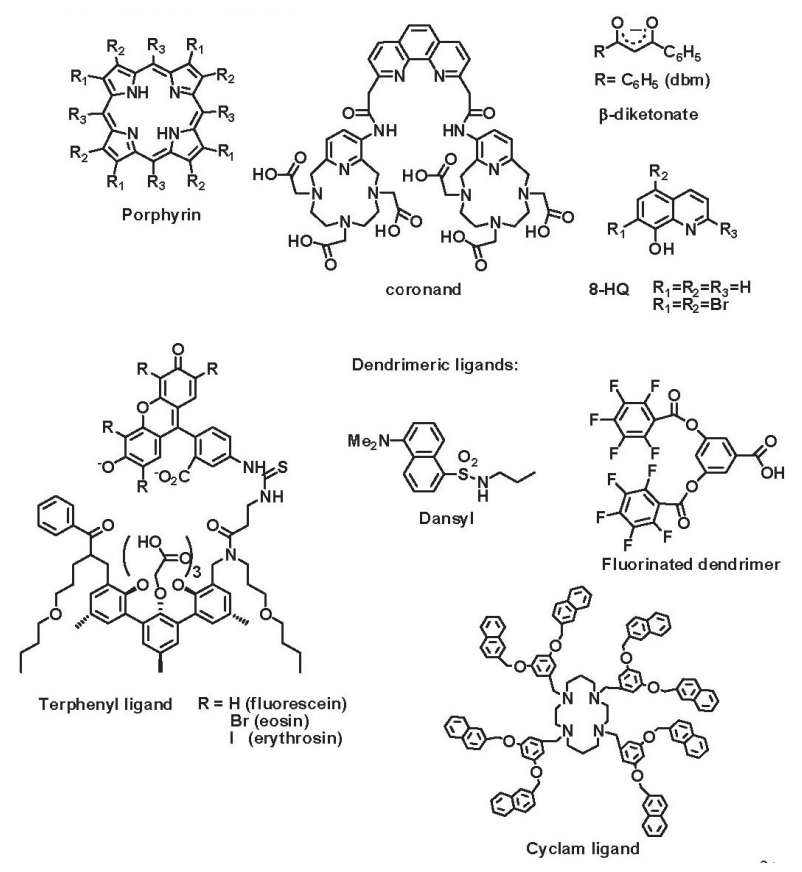

Scheme 1. Examples of ligands for the sensitization of NIR-emitting $\operatorname{Ln}^{3+}$ ions.
A coronandis a cyclic molecule containing several donor atoms in its ring such as cyclic ethers termed crown ethers. For example, bimetallic complexes with coronand are much more stable and they provide a tighter environment for the first coordination sphere of the metal ion. Ln (coronand) complexes display the highest quantum yields reported for $\mathrm{Yb}^{3+}$ complex in water $(0.53 \%)$.

In the case of acyclic ligands, lanthanide $\beta$-diketonates in 1897 by Urbain until now, hundreds of different complexes formed by reaction between $\mathrm{Ln}^{3+}$ ions and $\beta$-diketone derivatives have been described in the literature. ${ }^{20}$ These complexes have their potential application in diverse domain. In presence of lanthanide ions, $\beta$-diketonates generally form neutral tris complexes, [Ln $(\beta$-diketonate) 3 ], the delocalization of the negative charge of the ligand leading to the formation of stable six-membered chlate rings. Crosby and Kaska reported the NIR luminescence of trivalent $\mathrm{Yb}^{3+}$ ion between the organic liand, in this case dibenzoylmethanate (dbm), and the lanthanide ion. ${ }^{20}$

8 -Hydroxyquinoline $(8-\mathrm{HQ})$ is a bidentate ligand possessing good coordination properties towards a wide range of metal ions, including lanthanide ion. After the discovery of the $1.53 \mu \mathrm{m} \mathrm{Er}^{3+}$ luminescence in [Er (8-HQ) 3 ], where $8-\mathrm{HQ}$ is 8 -hydroxyquinolinate, in 1999 by Gillin et $\mathrm{al}^{9}{ }^{9}$ and subsequently metal-centred luminescence in the corresponding $\left[\mathrm{Nd}(8-\mathrm{HQ})_{3}\right]^{21}$ and $[\mathrm{Yb}(8-$ HQ) ${ }_{3}{ }^{22}$ complexes, several derivatives of this chromophore ${ }^{23,24}$, including podands ${ }^{25,26}$ and macrocycles ${ }^{27}$ have been proposed with success for the sensitization of $\mathrm{Nd}^{3+}, \mathrm{Er}^{3+}$, and $\mathrm{Yb}^{3+}$.

The acyclic $\mathrm{m}$-terphenylligand derivatized with carboxylic groups provides suitable coordination ability to efficiently encapsulate lanthanide ions. It has been fitted with chromophoric dyes such as triphenylene, dansyl, coumarin, lissamine, Texas red, fluorescein, eosin, erythrosine(see terphenyl ligand in Scheme 1) which have low-energy triplet states allowing sizeable sensitization of $\mathrm{Ln}^{3+} \mathrm{NIR}$ luminescence. ${ }^{28}$

In order to overcome the problem of very low $\mathrm{Er}^{3+}$ and $\mathrm{Nd}^{3+}$ quantum yields, these ions have been inserted into dendritic ligands. For $\mathrm{Nd}^{3+}$ ion, the light-harvesting chromophores chosen werethe dansyl group ${ }^{29,30}$, derivatized benzenetricarboxylate ${ }^{31,32}$, naphtyl moieties ${ }^{33}$, or a more intricate edifice in which light is transferred first onto a $\mathrm{Ru}^{2+}$ complex which sensitizes $\mathrm{Nd}^{3+}$ luminescence by means of the ${ }^{3} \mathrm{MLCT}$ state. ${ }^{34} \mathrm{For}_{\mathrm{Er}}{ }^{3+}$ ion, dansyl units are also adequate chromophores ${ }^{30}$, as well as metalloporphyrins. ${ }^{35-37}$

Very recently, to investigate the longer excitation wavelength of $\mathrm{Er}^{3+}$ ion in $\mathrm{Er}^{3+}$-doped fiber amplifiers (EDFA)s, $\mathrm{Er}^{3+}$ - chelated complexes have been focused on efficient energy transfer process between the emission of ligand and absorption of $\mathrm{Er}^{3+}$ ion (such as 600$750 \mathrm{~nm}$ region). Therefore, $\mathrm{Ln}^{3+}$ - cored complexes based on boron dipyrromethene (bodipy) ligands have been introduced for NIR emission. ${ }^{38}$

Two bodipy-based chromophores have been synthesized, which bear two methoxyphenyl substituents in the 1,7 positions and either hydrogen (L1) or bromine (L2) atoms in the 2,6 positions, with the aim of testing their ability to sensitize the luminescence of NIR emitting $\mathrm{Ln}^{3+}$ ions (see Figure1). Despite the presence of the two halogen 
substituents in L2, the two chromophores display very similar absorption and emission properties, the only difference being a drop in the quantum yield from $31 \%$ for L1 to $21 \%$ for L2. In addition, no triplet state emission could be evidenced for both chromophores as well as for their tris complexes with $\mathrm{Gd}^{3+}$ ions.

The experimental evidences reported here point to the bodipy framework being adequate for transferring energy onto NIR-emitting $\mathrm{Ln}^{3+}$ ions, with excitation in the orange region of the visible spectrum; in addition the complexes have high molar absorption coefficients $(\log \varepsilon \approx 5.0-5.2)$. While remaining modest, the amount of energy transferred from the ligands $(20-40 \%)$ is sizeable; the weak metalcentered luminescence observed at room temperature is mainly due to deactivation through high-energy vibrations, which explains why $\mathrm{Er}^{3+}$ complexes are less luminescent than their $\mathrm{Yb}^{3+}$ counterparts, as observed for complexes with a 8-hydroxyquinoline-derivatized bodipy ligand.

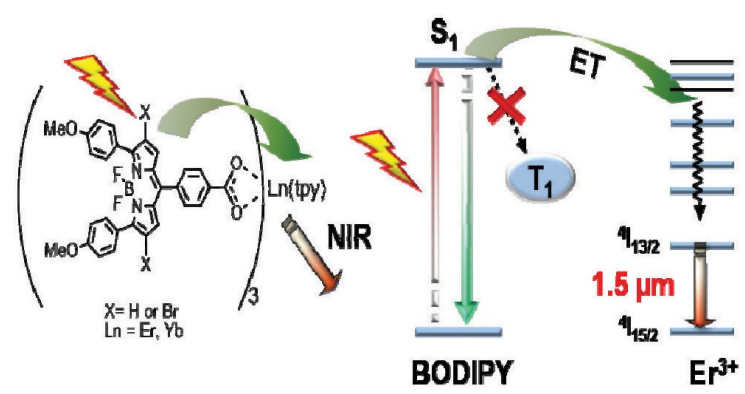

Figure 1. Chemical structures of lanthanide(III) - cored complexes based on bodipy ligands.

Up to date, luminescent $\mathrm{Ln}^{3+}$ complexes containing supramolecular ligands as antenna chromophores were not developed for the real use in various photonics applications, such as erbium-doped fiber amplifiers (EDFA), erbiumdoped waveguide amplifiers (EDWA) and light-emitting diodes. They are simply supramolecular complexes containing well-known antenna chromophores to photoexcite the $\mathrm{Ln}^{3+}$ ions via the energy transfer process. The quantum yield of energy transfer and the luminescence efficiency were not satisfied yet. Also, such efforts are just in the early stage and not only the basic concept not established, but also the structure-property relationship is not yet clearly understood. Therefore, the dependence of $\mathrm{Ln}^{3+}$ ion and ligand structure on amplification principles (such as the optical amplification lifetime, excited state dynamics, etc) need to be systematically established. Based on the relationship established, the design and synthesis of luminescent $\mathrm{Ln}^{3+}$ complexes using molecular engineering approach need to be investigated.

In this review, $\mathrm{Ln}^{3+}$ - cored complexes based on various organic ligands were overviewed for advanced photonics applications. $\mathrm{Ln}^{3+}$ ions were encapsulated by the luminescent ligands. Also, key parameters for emission enhancement and efficient energy transfer pathways for the sensitization of $\mathrm{Ln}^{3+}$ ions by luminescent ligands were investigated.

\section{Lanthanide Ions and Basic Optical Amplification Principle of Lanthanide Ions}

The electronic configurations of $\mathrm{Ln}^{3+}$ ions, referred to as the lanthanide ions or rare earth ions, have $4 f^{n}(\mathrm{n}=1 \sim 14)$ structures, which fill the $4 f$ orbital according to the atomic numbers starting from $\mathrm{Ce}^{3+}$ to $\mathrm{Lu}^{3+}$ ions. These ions all have an incompletely filled $f$ subshell in which the $f$-electrons are shielded by the outer $5 \mathrm{~s}$ and $5 \mathrm{p}$ electrons, which are lower in energy, but spatially located outside the $4 f$ orbitals. These electrons are slightly perturbed by the effects of lattice phonons and static strain fields in the coordination environment of ions, lead to the sharp spectral lines. Since the spin-orbit interaction is larger than the effect of the crystal field, the luminescence spectra consist of groups of lines which arise from crystal field splittings of $J$ multiplets of the free ion in general. ${ }^{39}$

Judd $^{40}$ and Ofelt ${ }^{41}$ independently derived expressions for the oscillator strength of induced dipole transitions within the $4 f^{n}$ - $4 f^{n}$ configuration. Since their results are similar and were published simultaneously, their results are known as the Judd-Ofelt theory. They summed over the intensities of the individual crystal field components of a given state.

The fundamental mechanism of the Judd-Ofelt theory is the perturbation caused by mixing of the crystal field potentials between the orbitals with different parities and $4 f^{n}$ orbitals. The $4 f^{\mathrm{n}}-4 f^{\mathrm{n}}$ transitions are forbidden because $4 \int^{\mathrm{n}}$ of rare earth ions and energy levels of electron shells have equal parity. However, absorption spectra between $4 f^{n}-4 f^{n}$ transition are experimentally observed. This is explained by assuming that a higher-lying opposite parity configuration is mixed into the $4 f^{\mathrm{n}}$ states via the potential due to the ligand field. ${ }^{42}$ In contrary, $4 f^{\mathrm{n}}-4 f^{\mathrm{n}-1} 5^{\mathrm{d} 1}$ transitions or charge transfer transitions $\left(4 f^{n}-4 f^{n^{1-1}} 5^{d 1}, \mathrm{~L}=\right.$ ligand) are partly allowed by mixing with the odd-parity wave functions via the potential due to the crystal field. The absorption and emission crosssections are very small in solid phase and the corresponding fluorescence decay times are sufficiently long (as of the order of ms), compared with the rate at which it is populated in the excitation process. Also there is a Stark splitting between the degenerated $4 f$ energy levels by the effect of electric field near $\mathrm{Ln}^{3+}$ ions removing the degeneracy of the $4 f$ level.

In analyzing the mechanisms of excited state relaxation of lanthanides in crystal hosts, two modes of relaxation are recognized: radiative and radiationless (or non-radiative) processes. $\mathrm{Axe}^{43}$ represented the radiative processes in quantitative terms using the Judd-Ofelt theory. Radiationless relaxation was formulated in terms of multiphonon relaxation processes. ${ }^{44,45}$ Such processes become less probable as the energy gap between an excited state and the next lower energy state increases. Since excited state relaxation is generally achieved prior to transitions to several lower-lying states, a total radiative relaxation rate can be defined as a summation over all states lower in energy than the fluorescing state. Scheme 2 shows the principal fluorescence states of the $\mathrm{Ln}^{3+}$ ions in crystal hosts. Fluorescence from many of these levels is observed 
only at low temperatures since rapid relaxation of an excited state by radiationless processes compete strongly with the radiative mode unless the energy gap to the next lower level is large. As the gap increases, the process rapidly decreases in probability such that radiative decay can efficiently compete with a relaxation mechanism. Usually both radiative and radiationless processes operate to relax an excited state. The total fluorescence lifetime of the state is a sum of the radiative rate and the rates of the various radiationless processes (see Scheme 2).

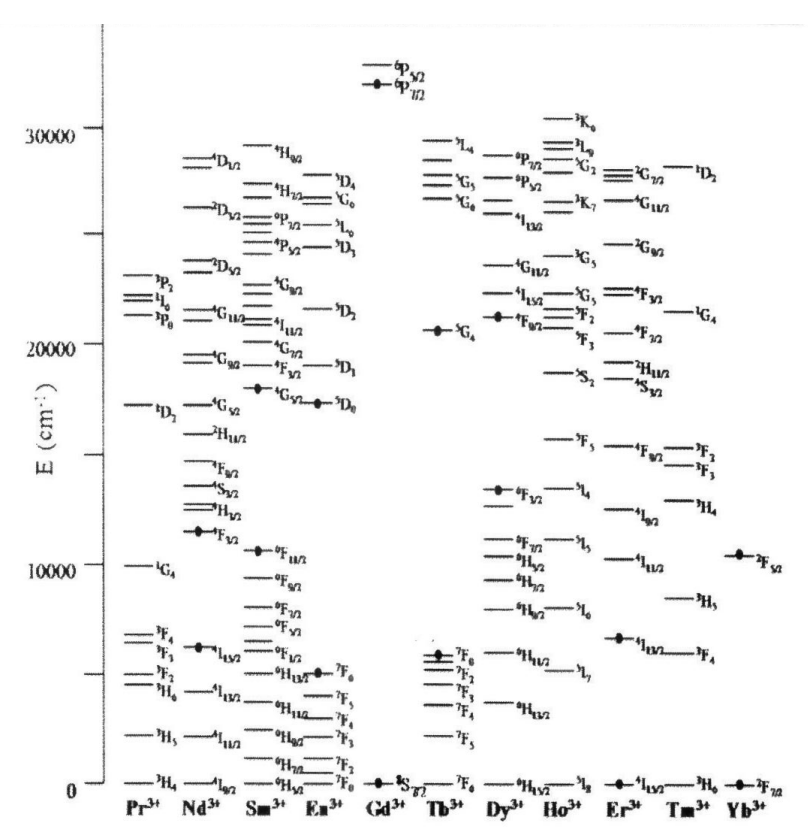

Scheme 2. Energy levels of $\mathrm{Ln}^{3+}$ ions.

Several lanthanide ions, such as $\mathrm{Pr}^{3+}, \mathrm{Nd}^{3+}, \mathrm{Dy}^{3+}, \mathrm{Er}^{3+}$, and $\mathrm{Yb}^{3+}$ ions, show luminescence in the near infrared region. The luminescence of wavelengths $1.53 \mu \mathrm{m}$ from $\mathrm{Er}^{3+}$ ion and $1.06 \mu \mathrm{m}$ from $\mathrm{Nd}^{3+}$ ion is used as standard wavelengths in optical communications, in which light is used to transport information between different users. Some of lanthanide ions, such as $\mathrm{Sm}^{3+}, \mathrm{Tb}^{3+}$ and $\mathrm{Eu}^{3+}$ ions, exhibit the emission band in the visible region. Their luminescent complexes have been considered the potential candidates for light-emitting diodes.

Among them, erbium-based materials have attracted much attention because they have the authentic optical amplification (OA) property with the strong stimulated emission band. This specific property renders erbiumbased materials to use in several photonics applications, such as erbium-doped fiber amplifiers (EDFA), erbium-doped waveguide amplifiers (EDWA) and light-emitting diodes. The basic optical amplification principle of $\mathrm{Er}^{3+}$ ion is described in Scheme 3. The $\mathrm{Er}^{3+}$ ion is excited to the upper energy level than the lower excited energy level $\left(\mathrm{Er}^{3+},{ }^{4} \mathrm{I} 13 / 2\right)$ of the lanthanide ions, by absorbing photons of pumping laser such as 488 or $980 \mathrm{~nm}$, etc. And then, the excited state of the upper energy level is transited to the lower excited energy level $\left(\mathrm{Er}^{3+},{ }^{4} \mathrm{I} 13 / 2\right)$ of the $\mathrm{Ln}^{3+}$ ions through the lattice relaxation process (or the vibrational relaxation process). The population inversion inherently takes place at the energy level of the lanthanide ions $\left(\mathrm{Er}^{3+},{ }^{4} \mathrm{I} 13 / 2\right)$. Finally, it loses the photon energy in a radiative decay to fall back to the ground state $\left(\mathrm{Er}^{3+},{ }^{4} \mathrm{I} 15 / 2\right)$ of the $\mathrm{Ln}^{3+}$ ions, emitting the stimulated light at $1.53 \mu \mathrm{m}$. When the same input signal with the metastable excited state is introduced at the same time, the input signal and the stimulated emission beam are summed to generate the amplified output signal, due to the power interchange between the input signal and the stimulated emission beam. The stimulated emission lifetime of the ${ }^{4} \mathrm{I} 13 / 2 \rightarrow{ }^{4} \mathrm{I} 15 / 2$ radiative transition at $1.53 \mu \mathrm{m}$ of $\mathrm{Er}^{3+}$ ion in a solid, which depends on the presence of impurities and defects in the host, is of the order of $10 \mathrm{~ms}$. In luminescent $\mathrm{Ln}^{3+}$ complexes, instead of direct excitation of $\mathrm{Er}^{3+}$ ion in a solid, the luminescent ligands, as photon sensitizers, efficiently absorb and transfer the light to excite the $\mathrm{Ln}^{3+}$ ions via an energy transfer between the luminescent ligand and the $\mathrm{Ln}^{3+}$ ion. It is very important to note that the accumulating photon energy from the excited state of the luminescent ligands can excite the $\mathrm{Ln}^{3+}$ ions as much as possible, thus enhancing the optical amplification gain (see Scheme 3).

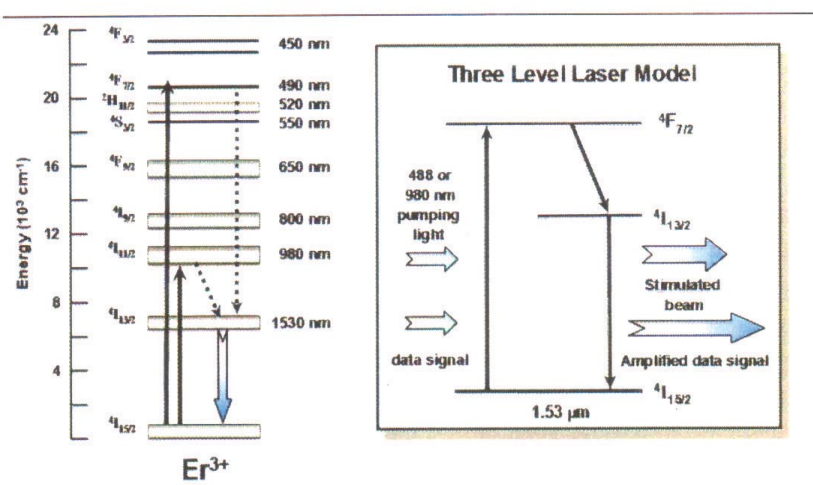

Scheme 3. Basic optical amplification principle of $\mathrm{Er}^{3+}$ ions for advanced photonics applications.

Efficient Energy Transfer Pathways for the Sensitization of $\mathrm{Ln}^{3+}$ Ions by Luminescent Ligands in Luminescent $\mathrm{Ln}^{3+}$ Complexes

To date, it is well-believed that only energy transfer from the triplet state of luminescent ligands to $\mathrm{Ln}^{3+}$ ion is the most dominant mechanism. ${ }^{46}$ Therefore, most researches toward lanthanide ion sensitizers have been focused on developing the luminescent ligands with a triplet state matching the receiving lanthanide ion energy levels. Interestingly, however, several reports mentioned the energy transfer from the excited singlet state to $\mathrm{Ln}^{3+}$ ion. ${ }^{47}$ We also reported all possible ET pathways using Pt-porphyrin $(\mathrm{ETt})^{35,37}$ and anthracene ligand $\left(\mathrm{ET} \mathrm{S}_{\mathrm{s}}\right)^{48}$, and additionally, demonstrated the unusual ET pathway through the intramolecular charge transfer (ICT) state of the naphthalene ligand to $\mathrm{Ln}^{3+}$ ion $(\mathrm{ETc})$ for the first time. ${ }^{49}$

To investigate all three possible ET pathways and compare 
the lanthanide emission efficiency for the various ET pathways in $\mathrm{Er}^{3+}$ - cored complexes, naphthalene derivatives $(\mathrm{NA}-0 \sim \mathrm{NA}-3)^{50}$ have been rationally designed and synthesized the structurally and UV-absorbingly similarligands and their stable 9 -coordinated $\mathrm{Ln}^{3+}-$ complexes. ${ }^{51}$ The energy transfer of the $\mathrm{Er}^{3+}-$ complex based on NA-2 takes places from the ICT state to $\mathrm{Ln}^{3+}$ ion. The $\mathrm{Er}^{3+}$ complexes based on NA-0 and NA-1 ligands have the ET mechanism via the excited triplet state. Brominesubstituted NA-1 ligand, as compared with NA-0 ligand, increases the rate of intersystem crossing (ISC) and decreases the fluorescence quantum yield, due to the internal heavy atom effect. In the case of $\mathrm{Er}^{3+}-[\mathrm{NA}-$ 3] 3 (tpy), the energy transfer takes place from the singlet state of NA-3 ligand to central $\mathrm{Er}^{3+}$ ion (see Figure 2). Although ET process via the triplet state to $\mathrm{Ln}^{3+}$ ion is considered as main efficient ET pathway in $\mathrm{Ln}^{3+}$ complex, this sensitization process is not strongly dominated on $\mathrm{Ln}^{3+}$ emission, compared with other ET pathways via singlet or charge transfer state.

Very recently, to enhance the luminescence properties of $\mathrm{Ln}^{3+}$ complexes, lanthanide complexes with two push-pull diketone derivatives as sensitizers have been developed for near-infrared emitting materials52 (see Figure 3-(a)).
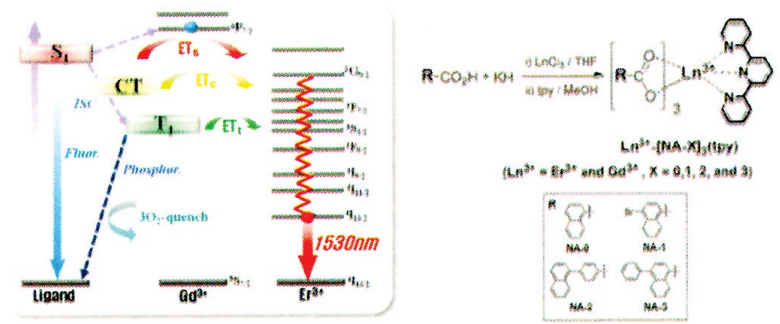

Figure 2. All possible ET pathways and chemical structures of lanthanide(III) - cored complexes based on naphthalene acid ligands.

The ligand substituents consist of a carbazole moiety with hole-transport properties and an aromatic or heteroaromatic unit. According to quantitative NMR analysis and complementary HPLC experiments, the diketones essentially appear under the thermodynamically stable enol form in solution displaying extended resonance electronic structure: the cis-enol tautomer amounts to $95-98 \%$ of the speciation in THF at room temperature. These ligands possess an intra charge-transfer(ICT) electronic state, the energy of which is sensitive to the polarity of the solvent and which allows convenient sensitization of the luminescence of NIR emitting ions such as $\mathrm{Nd}^{3+}$ and $\mathrm{Er}^{3+}$ in the visible spectrum. The resulting tris (diketonate) ternary complexes with terpyridine $(\mathrm{Ln}=\mathrm{Nd}$, Er $)$ display sizeable near-IR emission with long luminescence lifetimes. Upon excitation into the ICT band of the ligands, the spectra of the Er(III) compounds display the characteristic ${ }^{4} \mathrm{I} 13 / 2 \rightarrow{ }^{4} \mathrm{I} 15 / 2$ transition of $\mathrm{Er}^{3+}$ ion at 1530 $\mathrm{nm}$ (see Figure 3-(b)). It was also confirmed that the rate constant from singlet excited state to ICT state $\left(k \mathrm{I}_{\mathrm{cT}}\right)$ is larger than the rate constant of intersystem-crossing process $\left(k_{\mathrm{Isc}}\right)$. As a result, the new design criteria of lanthanide materials has been established to improve the luminescence intensity of $\mathrm{Ln}^{3+}$ ion by the ICT process, ${ }^{35,36,48}$, ${ }^{49}$ as compared with the existing theory of ET process via the triplet state to $\mathrm{Ln}^{3+}$ ion (see Figure 3-(c)).

Surprisingly, the ISC process caused by the heavy $\mathrm{Ln}^{3+}$ ion effect in $\mathrm{Ln}^{3+}$ complexes is not dominant process over the ICT or the radiative relaxation process and the ET process via the triplet state to $\mathrm{Ln}^{3+}$ ion is not strongly dominated on $\mathrm{Ln}^{3+}$ emission, compared with other ET pathways via singlet or charge transfer state. As concluded, no matter which ET pathway takes place, the key factor for strong lanthanide emission is the ET efficiency between the organic ligand and $\mathrm{Ln}^{3+}$ ion, associated with the quantum yield of a ligand and a proper $J$ value. This study can provide the criteria for designing the ligand to achieve efficient $\mathrm{Ln}^{3+}$ emission. ${ }^{50}$
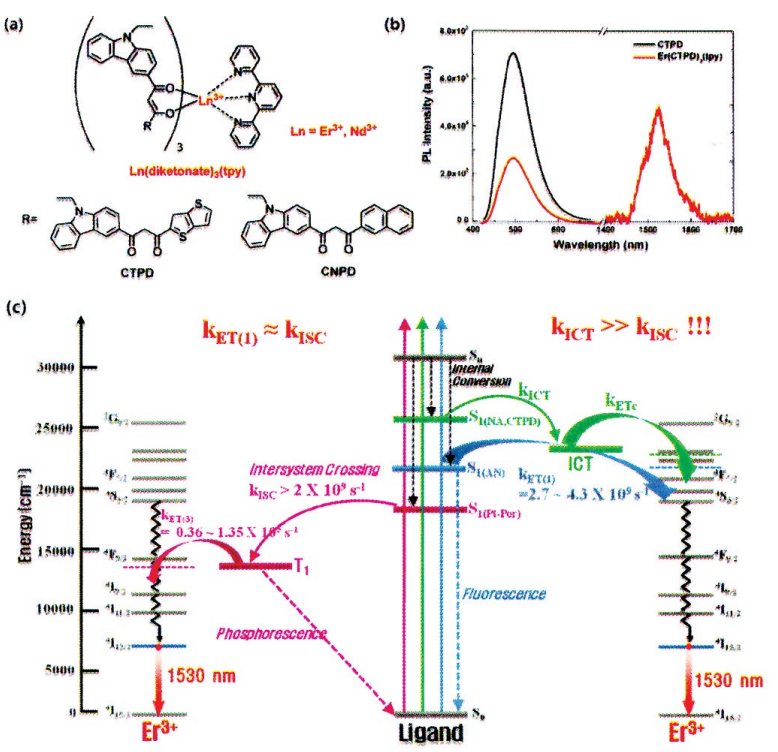

Figure3. (a) Scheme of [Ln(diketonate) 3 (tpy)] complexes $\left(\mathrm{Ln}=\mathrm{Er}^{3+}\right.$ and $\mathrm{Nd}^{3+}, \mathrm{R}=\mathrm{CTPD}$ and CNPD) (b) NIR emission spectra of CTPDand [Er(CTPD) 3 (tpy) $] 2.0 \times 10^{-5} \mathrm{M}$ in $\operatorname{MeCN}\left(\lambda_{e x}=410 \mathrm{~nm}\right)$. (c) Energy transfer diagram of CTPD complex by ICT process.

\section{$\mathrm{Er}^{3+}$-chelated Prototype Complexes: Key Parameters for Near IR Emission Enhancement}

To enhance the NIR emission intensity and maintain the effective energy transfer process, our research efforts have been focused on developing stable and inert $\mathrm{Er}^{3+}$ encapsulated complexes with artificial light-harvesting systems using dendritic luminescent ligands based on metalloporphyrins, naphthalenes, and anthracenes bearing the FrÖ)chet aryl-ether dendrons, namely, $\left(\mathrm{Er}^{3+}-[\mathrm{Gn}-\mathrm{Pt}-\right.$ Por $]_{3}(\text { terpy })^{35}, \mathrm{Er}^{3+}-[\mathrm{Gn}-\mathrm{Naph}]_{3}(\text { terpy })^{36}$ and $\mathrm{Er}^{3+}-[\mathrm{Gn}-$ $\mathrm{An}]_{3}$ (terpy) ${ }^{48}$ (see Scheme 4). 


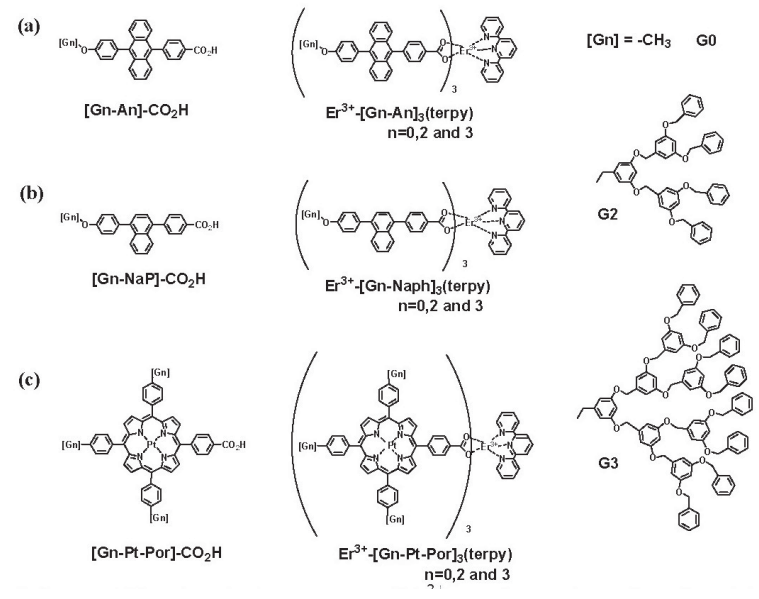

Scheme 4. The chemical structures of $\mathrm{Er}^{3+}-$ cored complexes based on (a) dendritic anthracene, (b) naphthalene and (c) $\mathrm{Pt}$-porphyrin ligands.

A series of inert and photostable encapsulated lanthanide(III) complexes based on dendritic anthracene ligands was shown for the first time to exhibit strong near-IR emission bands via efficient energy transfer from the excited states of the peripheral antenna to the $\mathrm{Ln}^{3+}$ ions $\left(\mathrm{Er}^{3+}, \mathrm{Yb}^{3+}\right.$, and $\left.\mathrm{Nd}^{3+}\right){ }^{37} \mathrm{~A}$ significant decrease in the fluorescence of the anthracene ligand was accompanied by a strong increase in the near-IR emission of the $\mathrm{Ln}^{3+}$ ions. The near-IR emission intensities of $\mathrm{Ln}^{3+}$ ions in the encapsulated $\mathrm{Ln}^{3+}$-dendrimer complexes are dramatically enhanced on increasing the generation number (n) of FrÖchet aryl-ether dendrons, owing to siteisolation and light-harvesting effects ${ }^{48}$ (see Figure 4).

(a)
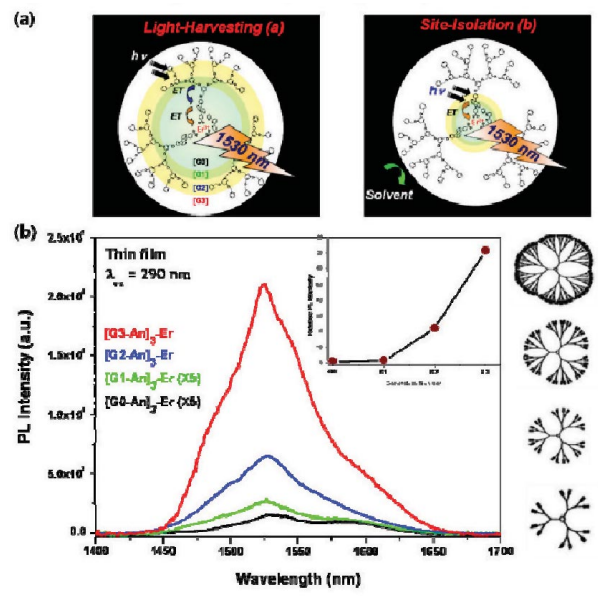

[G3]

$[G 2]$

$[\mathrm{GO}]$

Figure 4. (a) Schematics of the light-harvesting and siteisolation effects in a series of $\mathrm{Er}^{3+}-[\mathrm{Gn}-\mathrm{An}]_{3}$ (terpy) complexesenergy transfer. (b) Near-IR emission spectra of a series of $\mathrm{Er}^{3+}-[\mathrm{Gn}-\mathrm{An}]_{3}$ (terpy) inthin film upon photoexcitation at $290 \mathrm{~nm}$.

Furthermore, a first attempt was made to distinguish between the site-isolation and light-harvesting effects in the present complexes. Photophysical studies indicated the sensitization of $\mathrm{Ln}^{3+}$ luminescence by energy transfer through the excited singlet state of the anthracene ligands, and the energy-transfer efficiency between the dendritic anthracene ligands and the $\mathrm{Ln}^{3+}$ ion was evaluated to be in the range of 90 to $97 \%$. As a result, we observed that the NIR emission intensity of the lanthanide complexes was dramatically enhanced with increasing the generation number (n) of the Fré chet aryl-ether dendrons, due to the site-isolation and light-harvesting effects.

It was also demonstrated that a series of stable and inert $\mathrm{Er}^{3+}-$ cored complexes with dendritic $\mathrm{Pt}^{2+}-$ porphyrin ligands exhibit NIR emission bands via efficient energy transfer from the excited triplet state of the $\mathrm{Pt}^{2+}$ - porphyrin ligands to the $\mathrm{Er}^{3+}$ ions. ${ }^{35}$ The $\mathrm{Pt}^{2+}$ - porphyrin derivatives exerted a heavy $-\mathrm{Pt}^{2+}$-atom effect, leading to a higher intersystem crossing (ISC) efficiency for the conversion of a singlet state into a triplet state, as compared to the lighter $\mathrm{Zn}^{2+}$ - porphyrin derivatives. The NIR emission intensity of the lanthanide complexes was dramatically enhanced with increasing generation number (n) of the Fréchet aryl-ether-type dendrons, largely due to site-isolation and LH effects. Surprisingly, the site-isolation effect was dominant over the $\mathrm{LH}$ effect in the $\mathrm{Er}^{3+}-[\mathrm{Gn}-\mathrm{PtP}]_{3}$ (terpy) complexes due to the low quantum yield of the arylether dendrons $\left(\Phi_{\mathrm{f}}=\right.$ 0.02) for exciting $\mathrm{Pt}^{2+}$-porphyrin units. The NIR emission intensity of $\mathrm{Er}^{3+}-[\mathrm{G} 3-\mathrm{PtP}]_{3}$ (terpy) was seen to be 20times stronger than that of $\mathrm{Er}^{3+}-[\mathrm{G} 1-\mathrm{PtP}]_{3}$ (terpy), when comparing thin films of these complexes ${ }^{35}$ (see Figure 5).
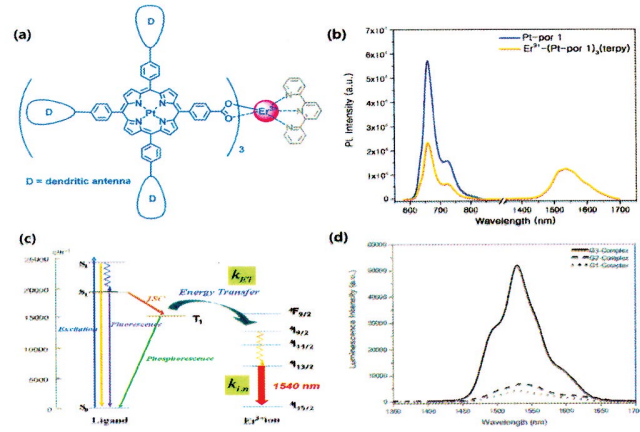

(d)

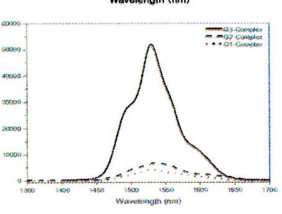

Figure 5. (a) Scheme of $\left[\mathrm{Er}(\mathrm{PtP})_{3}(\mathrm{tpy})\right]$ complexe (b) NIR emission spectra of $\mathrm{Pt}$-porphyrin ligand and $\left[\mathrm{Er}(\mathrm{PtP})_{3}(\mathrm{tpy})\right]$ in THF $\left(\lambda_{e x}=405 \mathrm{~nm}\right)$. (c) Energy transfer diagram of $\left[\mathrm{Er}(\mathrm{PtP})_{3}\right.$ (tpy) $]$ complex. (d) NIR emission spectra of $\mathrm{Er}^{3+}-$ $[\mathrm{Gn}-\mathrm{Ptp}]_{3}$ (terpy) complexes in thin film upon photoexcitation at $410 \mathrm{~nm}$.

Very recently, also, the photophysical criteriafor lanthanide emission enhancement for three Er(III) - cored dendritic complexes, such as $\mathrm{Er}^{3+}-[\mathrm{G} 2-\mathrm{An}]_{3}$ (terpy), $\left(\mathrm{Er}^{3+}-[\mathrm{G} 2-\right.$ $\mathrm{Pt}-\mathrm{Por}]_{3}$ (terpy), $\mathrm{Er}^{3+}-[\mathrm{G} 2-\mathrm{Naph}]_{3}$ (terpy) were investigated, as summarized in Table I.36The Er(III) - cored dendritic complex of $\mathrm{Er}^{3+}-[\mathrm{G} 2-\mathrm{An}]_{3}$ (terpy) exhibits the stronger PL intensity than the Er(III)-cored dendriticcomplex of $\mathrm{Er}^{3+}-[\mathrm{G} 2-\mathrm{Naph}]_{3}$ (terpy) or the Er(III) - coreddendritic complex of $\mathrm{Er}^{3+}-[\mathrm{G} 2-\mathrm{Pt}-$ Por $]_{3}$ (terpy) by 1.6 or 8.3 times, respectively, upon photoexcitation of the ligand at the absorption maximum wavelength. It may be due to the fact that the anthracene ligand in $\mathrm{Er}^{3+}-[\mathrm{G} 2-\mathrm{An}]_{3}$ (terpy) has a higher spectral overlap integral $(J)$ value and a higher luminescence quantum efficiency than naphthalene moiety or Pt(II) - porphyrin ligand in Er (III) - encapsulated dendrimer complexes. 
Table 1. Summary on photophysical results for lanthanide emission enhancement in luminescent lanthanide complexes

\begin{tabular}{|c|c|c|c|}
\hline & G2-An-Er(III) & G2-PtPor-Er(III) & G2-NA-Er(III) \\
\hline ET Pathway & Singlet state & Triplet state & ICT \\
\hline Relative $J$ & 3.4 & 1.0 & 2.3 \\
\hline ET Efficiency & $77 \%$ & $<77 \%$ & $100 \%$ \\
\hline$\Phi \operatorname{lig}$ & $\begin{array}{l}0.77 \\
\text { (solution) }\end{array}$ & $\begin{array}{c}0.45 \\
\text { (solution at } 77 \mathrm{~K} \text { ) }\end{array}$ & $\begin{array}{l}0.57 \\
\text { (solution) }\end{array}$ \\
\hline $\begin{array}{l}\text { Relative Intensity } \\
\text { of } \mathrm{Er} \text { (III) }\end{array}$ & 8.3 & 1.0 & 1.7 \\
\hline$\tau_{\mathrm{obs}}$ & $1.8 \mu \mathrm{s}$ & $1.65 \mu \mathrm{s}$ & $1.3 \mu \mathrm{s}$ \\
\hline$\Phi \mathrm{Ln}$ & $2.3 \times 10^{-4}$ & $2.1 \times 10^{-4}$ & $1.6 \times 10^{-4}$ \\
\hline
\end{tabular}

${ }^{a}$ Spectral overlap integral J value between ligand and erbium ion.

Therefore, to enhance of the NIR emission in luminescent lanthanide complexes, no matterwhich ET pathway takes place, the key parameters for NIR emission enhancement is as follows (1) The direct luminescent $\mathrm{Ln}^{3+}$ complexes have much higher PL efficiency than the indirect luminescent $\operatorname{Ln}^{3+}$ complexes. (2) Highly coordinated lanthanide-coredcomplexes (at least 8 to 9 coordination number) have muchhigher PL efficiency than unsaturated 6-coordinated complex. (3) The key factor for strong lanthanide emission is the ET efficiency between the organic ligand and $\mathrm{Ln}^{3+}$ ion, associated with the quantum yield of a ligand and a proper $J$ value.

\section{Summary and Outlook}

New synthetic methodology of the saturated and unsaturated $\mathrm{Er}^{3+}$-chelated prototype complexes based on metalloporphyrins, naphthalenes, anthracenes, push-pull diketone derivatives and bodipy ligands were successfully developed through the ligand-exchange reaction.

The stable and inert $\mathrm{Er}^{3+}$-encapsulated complexes based on anthracene, naphthalene, and $\mathrm{Pt}^{2+}$ - porphyrin ligands bearing a second generation FrÖchet aryl-ether dendron (G2) exhibit much stronger near-IR emission bands at $1530 \mathrm{~nm}$, originated from the $4 f^{n}-4 f^{n}$ electronic transition of the first excited state $\left({ }^{4} \mathrm{I} 13 / 2\right)$ to the ground state $\left({ }^{4} \mathrm{I} 15 / 2\right)$ of the partially filled $4 f$ shell. A strong decrease of fluorescence intensity of luminescent ligands, such as anthracene, naphthalene, and $\mathrm{Pt}^{2+}$ - porphyrin units, is accompanied by strongly increasing the near-IR emission of the $\mathrm{Er}^{3+}$ ions in $\mathrm{Er}^{3+}$-encapsulated dendrimer complexes, upon photoexcitation of luminescent ligands at the corresponding absorption maximum wavelength. It could be attributed to the efficient energy transfer process occurring between dendritic luminescent ligand and $\mathrm{Er}^{3+}$ ion. The emission intensity of the lanthanide complexes, upon photoexcitation of luminescent ligand at the corresponding absorption maximum wavelength, was dramatically enhanced by introducing a third generation Frechet aryl-ether dendron
(G3), as compared with those of their corresponding $\mathrm{Er}^{3+}-$ encapsulated complexes, mainly due to the site-isolation and LH effects. Surprisingly, the site-isolation effect was dominant over the $\mathrm{LH}$ effect in the $\mathrm{Er}^{3+}$-encapsulated complexes due to the low quantum yield of the aryl ether dendrons $\left(\Phi_{\mathrm{f}}=0.02\right)$.

From various researches, it can suggest that energy transfer pathway does not influence the lanthanide emission enhancement: Although ET process via the triplet state to $\mathrm{Ln}^{3+}$ ion is considered as main efficient ET pathway in $\mathrm{Ln}^{3+}$ complex, this sensitization process is not strongly dominated on $\mathrm{Ln}^{3+}$ emission, compared with other ET pathwaysvia singlet or charge transfer state. In other words, the ISC process caused by the heavy $\mathrm{Ln}^{3+}$ ion effect in $\mathrm{Ln}^{3+}$ complexes is not dominant process over the ICT or the radiative relaxation process.

Therefore, to enhance of the near-IR emission in luminescent lanthanide complexes, no matter which ET pathway takes place, the key parameters for NIR emission enhancement are the ET efficiency between the organic ligand and $\mathrm{Ln}^{3+}$ ion, associated with the quantum yield of a ligand and a proper $J$ value.

To determine the structure-property relationships, ultrahighly efficient light-harvesting supramolecular structures will be optimized and their application as the future optical amplification devices will be examined. Utilizing the developed materials, photonics community can have the leverage to lead the world in tomorrow's communication technology and the technological impact will be similar to the integrated circuit development in semiconductor industries. This will not only be considered to be the material revolution in the heart of exploratory materials in optical information and communication, but also will open up many new areas of applications of polymeric materials for use in ultrahigh speed communication and information systems for the future generation.

KEYWORDS Luminescent lanthanide complexes, Near infrared emission, Energy transfer pathways, Molecular design criteria, Advanced photonics applications

\section{ACKNOWLEDGEMENT}

This research was supported by a grant from the Fundamental R\&D Program for Core Technology of Materials funded by the Ministry of Knowledge Economy and World Class University program funded by the Ministry of Education, Science and Technology through the National Research Foundation of Korea (R31-2008-10035-0). 


\section{REFERENCES AND NOTES}

1. (a) Kim,H.K.:Roh,S.-G.;Hong, K.-S.; Ka, J.-W.;Baek, N.S.;Oh, J.B.; Nah, M.K.; Ma, S.M.;Cha, Y.H.; Ko, J. Macromol. Res. 2003, 11, 133-145.(b) Kim, H. K.; Oh, J.B.; Baek, N. S.; Roh, S.-G.; Nah, M. K.; Kim, Y.H. Bull.Kor.Chem.Soc. 2005,26,201-214.

2. Desurvire, E;.Erbium-dorped Fiber Amplifiers: Principles and Applications, John Wiley \& sons, Inc., New York, 2002, vol. 2, 1 77

03. Oude Wolbers, M. P.; van Veggel,F.C.J.M.;Peters, G.A.;van Beelen, E. S. E.; Hofstraat, J. W.; Guerts, F. A. J.; Reinhoudt, D. N. Chem. Eur. J. 1998, 4, 772-780.

4. Slooff, L. H.;Polman, A.; Oude Wolbers, M. P.; van Veggel, F. C. J. M.; Reinhoudt, D. N.; Hofstraat, J. W. J. Appl. Phys. 1998, 83, 497-503.

5. Klink, S. I.; Reinhoudt, D. N.; van Veggel, F. C. J. M.;Werts, M. H. V.; Guerts, F. A. J.; Hofstraat, J.W. J.Phys.Chem. A. 2000,104, 5457-5468.

6. Slooff, L. H.; Polman, A.;Klink, S. I.; Hebbink, G. A.; Grave, L. vanVeggel, F.C.J.M.; Reinhoudt, D. N.; Hofstraat, J. W. Opt. Mater. 2000, 14, 101-107.

7. Slopff,L.H.;Polman, A.;Cacialli, F.;Friend, R. H.; Hebbink, G. A.; van Veggel, F. C. J. M.; Reinhoudt, D. N. Appl. Phys.Lett. 2001, 78, 2122-2124.

8. Werts, M. H. V.; Hofstraat, J. W.; Geurts, F. A. J.;Verhoever, J. W. Chem. Phys. Lett. 1997, 276, 196201.

9. Gilllin, W. P.; Curry R. J. Appl. Phys. Lett.1999, 74,798-799.

10. Curry, R. J.;Gillin, W.P. Appl. Phys. Lett. 1999, 75, 1380-1382.

11. Thompson, J.; Blyth, R. I. R.; Gigli, G.; Cingolani, R. Adv. Funct. Mater. 2004, 14, 979-984.

12. Kawamura, Y.; Wada, Y.; Hasegawa, Y.;Iwamuro, M.; Kitamura, T.; Yanagita, S. Appl. Phys. Lett. 1999, 74, 3245-3247.

13. Hasegawa, Y; Ohkubo, T.; Sogabe, K.;Kawamura, Y.;Wada, Y.; Nakashima, N.; Yanagita, S. Angew, Chem, Int. Ed. Engl. 2000, 39, 357-360 .

14. Kang, T-S.; Harrison, B. S.; Foley, T. J.; Knefely, A. S.; Boncella, J. M.; Reynolds, J. R.; Schanze, K. S. Adv. Mater. 2003, 15, 1093-1097.

15. Kawa M.; Fré chet, J. N. J. Chem. Mater. 1998, 10, 286-296.

16. Gschneidner, K. A. Jr.Bunzli, J.-C. G.; Percharsky V. K. Eds. Handbook on the Physics and Chemistry of Rare Earths, Elsevier B.V., Amsterdam, 2007, vol. 37, pp. 217-470.

17. Korovin, Y. V.;Rusakova, N. V. Rev. Inorg. Chem. 2001, 21, 299-329.

18. Wang, Q. M.; Sasaki, S.;Tamiaki, H. Chem. Lett. 2009, 38, 648-649.

19. Andrews, M.; Ward, B. D.; Laye, R. H.; Kariuki, B. M.; Pope, S. J. A. Helv. Chim. Acta.2009, 92, 2159-2172.

20. Crosby, G. A.; Kasha, M. Spectrochim. Acta. 1958, 10, 377-382.

21. Khreis, O. M.; Curry, R. J.; Somerton, M.;Gillin, W. P. J. Appl. Phys. 2000, 88, 777-780.

22. Khreis, O. M.;Gillin, W. P.; Somerton, M.; Curry, R. J.Org.Electr.2001, 2, 45-51.
23. Albrecht, M.;Osetska, O.;Klankermayer, J.;Fröhlich, R.;Gumy, F.;Bünzli, J. C. G. Chem. Commun. 2007, 18, $1834-1836$.

24. Shavaleev, N. M.;Scopelliti, R.;Gumy, F.;Bünzli, J. C. G. Inorg. Chem. 2009, 48, 7937-7946.

25. Samuel, J.;Tallec, G.;Cherns, P.; Ling, W. L.;Raccurt, O.;Poncelet, O.;Imbert, D.;Mazzanti, M. Chem. Commu. 2010, $462647-2649$.

26. Nonat, A.;Imbert, D.;P?caut, J.; Giraud, M.;Mazzanti, M. Inorg. Chem. 2009, 48. 4207-4218.

27. He, H.; May, P. S.;Galipeau, D. Dalton Trans. 2009, 24, 4766-4771.

28. Hebbink G. A.; Grave, L.;Woldering, L. A.;Reinhoudt, D. N.; VanVeggel, F. C. J. M. J. Phys. Chem. 2003, 107, 2483-2491.

29. VÖgtle, F. Gorka, M.;Vicinelli, V.;Ceroni, P.;Maestri, M.:Balzani, V. Chem. Phys. Chem. 2001, 2, 769-773.

30. Vicinelli, V.; Ceroni, P.; Maestri, M.; Balzani, V. J. Am. Chem. Soc. 2002, 21, 6461-6468.

31. Pitois, C.;Vestberg, R.; Rodlert, M.;Malmstrom, E.;Hult, A.; Lindgren, M. Opt. Mater. 2003, 21, 499-506.

32. Pitois, C.;Hult, A.; Lindgren, M. J. Lumin.2005, 111, 265-283.

33. Saudan, C.;Ceroni, P.;Vicinelli, V.;Maestri, M.;Balzani, V.;Gorka, M.; Lee, S.K.; van Heyst, J.;Vogtle, F.Dalton Trans. 2004, 10, 1597-1600.

34. Giansante, C.;Ceroni, P.;Balzani, V.;VÖgtle, F. Angew. Chem. Int. Ed. 2008, 47, 5422-5425.

35. (a) Oh, J.B.; Nah, M. K.; Kim, Y. H.; Kang, M. S.; Ka, J. W.; Kim, H. K. Adv. Funct. Mater. 2007, 17, 413-424. (b) Nah, M. ?K.; Oh, J. B.; Kim, H. K.; Choi, K. -H.; Kang, J.-G. J. Phys. Chem. A. 2007, 111, 6157-6164.

36. Kim, Y. H.; Baek, N. S.; Oh, J.B.; Nah, M. K.; Roh, S. -G.; Song, B. J.; Kim, H. K. Macromol. Res. 2007, 3, 272279.

37. Oh, J. B.; Kim, Y. H.; Nah, M. K.; Kim, H. K. J. Lumin. 2005, 111, 255-264.

38. Ryu, J. H.Eom, Y. K.Bünzli, J.-C. G. Kim,H. K. New J. Chemistry. 2011, 36, 723-731.

39. Kaplyanskii, A. A; Kaplyanskii, R. M. Spectroscopy of Solids Containing Rare Earth Ions., North-Holland: Amsterdam, 1987, vol. 21, $51-184$.

40. Judd, B. R. Phys. Rev. 1962, 127, 750-761.

41. Ofelt, G. S. J. Chem. Phys. 1962, 37, 511-520.

42. Wybourne, B. G. Spectroscopic Properties of Rare Earths; Interscience: New York, 1965

43. Axe, J. D. J. Chem. Phys. 1963, 39, 1154-1160.

44. Barasch, G. E.; Dieke, G. H. J. Chem. Phys. 1965, 43, 988-994.

45. (a) Riseberg, L. A.; Moos, H. W. Phys. Rev. Lett. 1967, 19, 1423-1426. (b) Riseberg, L. A.; Moos, H. W. Phys. Rev. 1968, 174, 429-438.

46. Oude Wolbers, M. P.; van Veggel, F. C. J. M.; SnellinkRuel, B. H.M.; Hofstraat, J. W.; Geurts, F. A. J.; Reinhoudt, D. N. J. Am.

Chem. Soc. 1997, 119, 138-144.

47. Hebbink, G. A.; Klink, S. I.; Grave, L.; Alink, P. G. B. O.; van Veggel, F. C. J. M. ChemPhysChem. 2002, 3, 1014-1018. 
48. Baek, N.S. Kim, Y. H.; Roh, S.-G. Kwak, B. K.; Kim, H. K, Adv. Funct. Mater. 2006, 16, 1873-1882.

49. Kim, Y. H.; Baek, N. S.; Kim, H. K. ChemPhysChem 2006, 7, 213-221.

50. Baek, N.S.; Kim, Y. H.; Kim, H. K, Bull. Kor. Chem. Soc. 2006, 27, 1729-1730.

51. Roh, S.-G.; Baek, N. S.; Hong, K.-S.; Kim, H. K. Bull. Kor. Chem. Soc. 2004, 25, 343-344.

52. Baek, N. S.; Kim, Y. H.; Eom, Y. K.; Oh, J. H.; Kim, H.K.; Aebischer, A.; Gumy, F.; Chauvin, A.-S.; Bünzli, J.-C.G. Dalton Trans. 2010, 39, 1532-1538. 